\title{
To Anticoagulate or Not? That Is the Question. Management of High-Risk Patients with Mechanical Mitral and Double Valves: A Case Series
}

\author{
Mark Joseph, MD \\ Carilion Cardiothoracic Surgery, Department of Surgery, Virginia Tech-Carilion School of Medicine, Roanoke, Virginia, USA
}

\section{ABSTRACT}

The Achilles heel of mechanical valves appears to be the need for anticoagulation. Several different types of mechanical valves have come and gone. The success or lack thereof of these valves depended on their various designs. We compared the two most promising mechanical valves of different eras and the need for anticoagulation through a case review. Both the Medtronic-Hall tilting disc valve and the bileaflet On- $\mathrm{X}$ valve were compared and contrasted in terms of durability and management of anticoagulation in high-risk patient populations. We present two cases of challenging anticoagulation management: a patient who underwent a mitral valve replacement with a Medtronic-Hall tilting disc valve who was off anticoagulation for close to six years, and a patient who underwent $\mathrm{On}-\mathrm{X}$ mitral and aortic valve replacements and suffered a subsequent intracranial bleed requiring surgical intervention. We explore the ethical dilemmas associated with these patients and the risk of restarting anticoagulation for each.

\section{INTRODUCTION}

Anticoagulation for both mechanical and tissues valves have been debated extensively. There is wide variability of practice in terms of anticoagulation in patients with bioprosthetic valves. The current American Heart Association guidelines recommend anticoagulation of patients with tissue valves with a vitamin $\mathrm{K}$ antagonist for 3 months and maybe even up to 6 months, despite small studies showing there is no benefit [Nishimura 2017; Sundt 2005; ElBardissi 2010]. This controversy has become even more relevant in transcatheter aortic valve replacement (TAVR), with studies in TAVR patients with tissue valves showing increasing potential for thrombus formation in the early postoperative period. The notion of clot formation and potential of clinical thromboembolism, however, remains unclear [Hansson 2016; Makkar 2015]. Anticoagulation for mechanical valves has changed over the last several years. A majority of patients

Received April 2, 2018; March 11, 2019.

Correspondence: Mark Joseph, MD, 2001 Crystal Spring Ave, Suite 201, Roanoke, VA 24014; (540) 853-0110; fax: (540) 342-9308; email: mjoseph@ carilionclinic.org. with mechanical valves in the aortic position have been historically managed with an international normalized ratio (INR) in the 2-3 range while those with mechanical valves in the mitral position have been maintained with an INR in the 2.5-3.5 range [Nishimura 2017]. This practice was true until the On-X mechanical heart valve (On-X Life Technologies, Austin, TX, USA) came to the market. The PROACT trial, which explored lower anticoagulation in mechanical valves, showed that maintaining decreased INR levels at 1.5-2 after 3 months of standard anticoagulation is satisfactory [Puskas 2014; Puskas 2018]. Because of the lack of long-term durability of tissue valves, as clinicians we have struggled with the decision-making process for choosing between a bioprosthetic valve and a mechanical valve for high risk but younger patients. Most clinicians would choose to place a mechanical valve in a young, otherwise healthy individual. But what if this patient then becomes high-risk due to a GI bleed or intracranial hemorrhage, or decides to have children after implantation, or even worse, becomes non-compliant? There are no current recommendations regarding such circumstances nor can anyone accurately predict these scenarios. We present two cases of relatively young males who presented clinically as high risk on either end of the anticoagulation spectrum: one with a significant bleed and the other with a potential for thrombosis and valve dysfunction from being off anticoagulation. We discuss the anticoagulation management strategy of both and explore the ethical dilemmas surrounding these scenarios.

\section{CASE I}

A 51-year-old male who was seen for a newly diagnosed cavitary lung nodule presented to his PCP with reports of dyspnea, cough, and hemoptysis. A chest radiograph revealed $2.5 \times 1.4 \mathrm{~cm}$ opacity in the left upper lobe and a nonspecific opacity in the right lung. He was diagnosed with pneumonia and started on antibiotics. A chest CT scan performed shortly thereafter showed a spiculated cavitary nodule in the left upper lobe that measured $2.4 \times 2.2 \times 1.6 \mathrm{~cm}$, and it was also FDG avid on PET scan. During his workup for possible surgical resection, he was found to have had a mechanical valve mitral valve replacement (MVR) in 2000 with a MedtronicHall valve. Post-MVR, he had remained on anticoagulation with Coumadin until 2010 when he was lost to follow up, became unemployed, and was unable to afford any medication. His social situation then more recently improved, and 
he saw a physician to begin workup for his lung lesion. He had a history of 33 packs per year of smoking and continued to smoke.

An echocardiogram demonstrated a normal functioning valve with no evidence of thromboembolism or pannus involvement. The patient subsequently underwent lung resection off anticoagulation and did well. The question remained whether he should re-start anticoagulation, after being off anticoagulants for more than 6 years.

\section{CASE 2}

We present the case of a 38-year-old male who initially presented with what appeared to be isolated mitral valve prolapse with severe mitral regurgitation (MR) from a flail P2 leaflet. His ejection fraction (EF) at the time was $25 \%$ with mild aortic insufficiency (AI). He underwent a mitral valve repair with a $\mathrm{P} 2$ leaflet excision and annuloplasty ring with excellent postoperative results. His pathology, however, came back positive for Loeys-Dietz Syndrome (LDS) based off of the mitral leaflet pathology. Subsequent genetic testing showed he was positive for an acquired variant of LDS. He was closely monitored clinically with serial echocardiograms, and was found to have progressive dilation of his aortic root and return of his MR a little over a year after his surgery. His aortic root measured $5 \mathrm{~cm}$ with mild aortic insufficiency (AI); however, his EF had dramatically improved to normal despite the return of his MR. A little more than a year after his mitral valve repair, he subsequently underwent a redo sternotomy for double valve replacement-an aortic root replacement with an On-X valve conduit in the aortic position and a mitral valve replacement with an $\mathrm{On}-\mathrm{X}$ valve. His postoperative course was routine and he and was discharged on Coumadin with a goal INR of 2.5-3.5, using the higher INR recommendation for an On-X mitral valve. Within 24 hours of discharge, the patient was brought into the emergency room with symptoms of left-sided paresis and dysarthria. A CT scan of the head revealed a large intracranial bleed with midline shift, in the face of a sub-therapeutic INR of 2 . He was emergently taken for decompressive craniectomy with reversal of his anticoagulation. Postoperatively, his anticoagulation was re-initiated with heparin once it was determined to be safe from a neurosurgical standpoint. He was eventually bridged to Coumadin with an INR kept on the lower end of a 1.5-2 range, given his intracranial hemorrhage. He had significant recovery with only mild short-term memory loss and mild word finding capability but with full return of strength and speech. His postoperative echocardiogram three months later revealed no evidence of thrombosis on either valve leaflets, despite a sub therapeutic INR in the range of 1.5-2.

\section{DISCUSSION}

Anticoagulation management following mechanical cardiac valve replacement revolves around target levels for chronic oral anticoagulation. According to Emery et al, this is only one aspect of a follow-up process that should be individualized to each patient along with patient education, risk factor modification, and long-term follow-up. Patient-related risk factors, such as atrial fibrillation, hypertension, smoking, need for surgery, or bleeding diathesis markedly increase the incidence of potential valve-related events requiring intense management during the postoperative period [Emery 2008]. In addition to these risk factors, anatomic position of valves also plays a role. The aortic valve position is the safest of all the anatomic positions for likelihood of valve-related events, with the mitral valve and tricuspid being riskier based on blood flow dynamics. There is little data available for anticoagulation in situations where patient- specific factors pose a risk. In both of our cases, the patients had mechanical valves in either the mitral or both the aortic and mitral positions, making anticoagulation likely necessary but risky at the same time. The properties of the two different valves used in these scenarios may have contributed to the need for little or no anticoagulation.

The Medtronic-Hall valve was introduced into clinical use toward the end of 1977 and stayed in production until 2009. It was initially introduced as the Hall-Kaster valve, named for both the surgeon and the engineer who developed it, Karl Hall and Robert Kaster. The reasons that production of this valve ceased are unclear, but were likely due to the increasing market for bileaflet valves. The tilting disc valve was arguably considered to be the best mechanical valve created in terms of longevity and complications. It continued to be implanted for several years after the end of production, due to its durability and following within the surgical community [Antunes 2015]. The properties that allowed this valve to be widely regarded related to its low complication rate included the tilting axis, the disc, and its guidance mechanism, and its ability to move away from the housing during opening. This reduced valve thrombosis and improved flow through both orifices of the open valve [Nitter-Hauge 1979].

The Medtronic-Hall valve was always classified among the least thrombogenic of all mechanical valves [Vahanian 2012]. In fact, it was shown to have a low incidence of thrombosis and thromboembolism in a less compliant third-world population [Antunes 1988; Kinsley 1983]. Not only did it have low rates of thromboembolism and endocarditis, but it also achieved excellent outcomes with survival and freedom from reoperation, compared to the valves of its era and of contemporary valves still in use today [Butchart 2001; Svennevig 2007; Butchart 1988; Williams 2004]. To date, the On-X valve seems to be the closest to the Medtronic-Hall valve in terms of rates of thromboembolic phenomena and requires less anticoagulation in the aortic position [Puskas 2014; Puskas 2018; Vahanian 2010]. Similar to the Medtronic-Hall valve, the On-X may be effective in a less compliant or thirdworld population, which is especially important in the mitral position [Vahanian 2010; Kinsley 1983; Butchart 2001].

Current data show that in the aortic position, a lower INR range is well tolerated in On-X valves [Puskas 2014; Puskas 2018]. To date, there is one case report of a patient on reduced or no anticoagulation with double $\mathrm{On}-\mathrm{X}$ valves in the aortic and mitral positions, with no evidence of thrombus on 
subsequent echocardiography at five months [Karkar 2015]. There are also case series demonstrating the safety of pregnancy in patients on minimal anticoagulation [Williams 2006]. Ongoing studies, however, are needed to guide definitive anticoagulation therapy in patients with $\mathrm{On}-\mathrm{X}$ valves. Several researchers have studied and advocated for a lower INR range for On-X mechanical mitral valves [Xu 2016; Chan 2010]. A meta-analysis of 14 studies with 3595 patients with mechanical mitral valves showed reduction in major hemorrhage and major total events in the low intensity group (INR $<2.5)$ as compared with high intensity group (INR 2.5-3.5), with no difference noted in major thromboembolism. This metaanalysis evaluated three different valves, including the On-X valve [Xu 2016]. In addition, a recent prospective observational study done in Canada showed that in 737 patients who underwent $\mathrm{On}-\mathrm{X}$ valve replacements in aortic and/or mitral positions had a 5 -year freedom from major thromboembolism and hemorrhage rate for aortic valve replacement of $96.5 \%$ and $93.6 \%$, with a rate of $97.7 \%$ and $95.7 \%$ for MVR. These patients were maintained at a lower therapeutic INR range (INR of 2.0-2.5 for AVR and 2.0-3.0 for MVR), regardless of other risk factors such as atrial fibrillation [Chan 2010].

Based on the early results of the PROACT trial, the On-X valve was approved for lower therapeutic INR range than its competitors [Puskas 2014]. The construction of the valve itself uses pure pyrolytic carbon as opposed to silicon carbide, which may lend itself to increased biocompatibility with better hemodynamics, and likely decreased rates of thromboembolism. In addition, the flared inlet and ninety-degree opening of the leaflets may also make it less thrombogenic [Ely 1998]. Theoretically, if the design of the On-X valve is superior in that it does not require the higher INR range in the aortic position, one would infer that this would be true in the mitral position as well. However, the low flow state in the mitral position and greater likelihood of propagation of clot could further cause double valve failure in such a situation [Emery 2008]. It may be that the construction and properties that allow better flow dynamics may contribute to a valve that is hemodynamically superior to that of its contemporaries.

It has already been shown that the On-X valve may have a slightly better hemodynamic profile than the St. Jude mechanical valve (St. Jude Medical, St. Paul, MN, USA) and Carbomedics Top Hat valve (Carbomedics, Austin, TX, USA) in the aortic position, the clinical significance of which is unknown [Butchart 2001; Chambers 2005; Walther 2000]. However, in the mitral position, the hemodynamics were comparable except for smaller mitral sizes of $<25 \mathrm{~mm}$, where the On-X valve had a higher estimated orifice area and index (EOA and EOAI), which may explain a lower thromboembolic rate in a poorly anticoagulated group [Butchart 2001; Mostafa 2018].

In the case of the patient with the Medtronic-Hall valve, several ethical questions remain. First, how do you convince a patient to restart anticoagulation for a mechanical valve when he has had no issues for over 6 years? Second, how do you justify the increased morbidity of anticoagulation with aging, especially in a patient who has had hemoptysis or another bleeding diathesis? If there is indication for anticoagulation now, what INR range should the provider choose?
With the On-X valve, if it proves a lower INR range is acceptable in the mitral position, then the next obvious question is whether these patients and valves can survive on novel oral anticoagulation (NOAC) alone rather than warfarin. Additionally, other questions remain to be answered. Is improved valve hemodynamics inversely proportional to the level of anticoagulation? If this concept is true for mechanical valves, does it hold true for biological or even native valves? Can anticoagulation halt the progression of failure in biological and native valves? These issues remain controversial and these questions remain unanswered. Further trials will hopefully further address some of these issues and concerns. In the meantime, complex care decisions should be individualized based on the patient, and ideally be discussed in a multidisciplinary setting. In our case, we referred the first patient back to his cardiologist and primary care physician with the recommendation that the patient likely should restart anticoagulation.

This report reiterates the durability of the Medtronic-Hall and the On-X mechanical valves in a high-risk or noncompliant population with little or no anticoagulation in the aortic and/or mitral position. Further studies are needed in order to continue to push the limits of minimizing anticoagulation in these complex patients.

\section{REFERENCES}

Antunes MJ, Wessels A, Sadowski RG, et al. 1988. Medtronic-Hall valve replacement in a third-world population group: a review of the performance of 1000 prostheses. J Thorac Cardiovasc Surg 95:980-93.

Antunes MJ. 2015. Requiem for a good mechanical heart valve: Farewell to the Medtronic Hall valve. J Thorac Cardiovasc Surg 149:1492-4.

Butchart EG, Lewis PA, Grunkemeier GL, Kulatilake N, Breckenridge IM. 1988. Low risk of thrombosis and serious embolic events despite low intensity anticoagulation: experience with 1,004 Medtronic-Hall valves. Circulation 78:66-77.

Butchart EG, Hui-Hua L, Payne N, Buchan K, Grunkemeier GL. 2001. Twenty years' experience with Medtronic Hall valve. J Thorac Cardiovasc Surg 121:1090-1100.

Chambers J, Roxburgh J, Blauth C, O'Riordan J, Hodson F, Rimington H. 2005. A randomized comparison of the MCRI On-X and CarboMedics Top Hat bileaflet mechanical replacement aortic valves: Early postoperative hemodynamic function and clinical events. J Thorac Cardiovasc Surg 130:759-64.

Chan V, Jamieson WR, Lam BK, et al. 2010. Influence of the On-X mechanical prosthesis on intermediate-term major thromboembolism and hemorrhage: A prospective multicenter study. J Thorac Cardiovasc Surg 140:1053-8.e2.

ElBardissi AW, DiBardino DJ, Chen FY, et al. 2010. Is early antithrombotic therapy necessary in patients with bioprosthetic aortic valves in normal sinus rhythm? J Thorac Cardiovasc Surg 139:1137-45.

Ely JL, Emken MR, Accuntius JA, et al. 1998. Pure pyrolytic carbon: Preparation and properties of a new material, On-X carbon for mechanical heart valve prostheses. J Heart Valve Dis 7:626-32.

Emery RW, Emery AM, Raikar GV, Shake JG. 2008. Anticoagulation for mechanical heart valves: a role for patient based therapy. J Thromb Thrombolysis 25:18-25. 
Hansson NC, Grove EL, Andersen HR, et al. 2016. Transcatheter aortic valve thrombosis: incidence, predisposing factors, and clinical implications. J Am Coll Cardiol 68:2059-69.

Karkar AM, Castresana MR, Odo N, Agarwal S. 2015. Anticoagulation dilemma in a high-risk patient with On-X valves. Ann Card Anaesth 18:257-60.

Kinsley RH, Colsen PR, Antunes MJ. 1983. Medtronic-Hall valve replacement in a Third World population group. Thorac Cardiovasc Surg 31:69-72.

Makkar RR, Fontana G, Jilaihawi, H, et al. 2015. Possible subclinical leaflet thrombosis in bioprosthetic aortic valves. N Engl J Med 373:2015-24.

Mostafa EA, El Midany AA, Taha AS, et al. 2018. On-X versus St Jude Medical mechanical prosthesis, in mitral position: are we moving forward in design technology? J Cardiovasc Surg (Torino) 59:252-8.

Nishimura RA, Otto CM, Bonow RO, et al. 2017. AHA/ACC Focused Update of the 2014 AHA/ACC Guideline for the Management of Patients With Valvular Heart Disease: A Report of the American College of Cardiology/American Heart Association Task Force on Clinical Practice Guidelines. J Am Coll Cardiol 70:252-89.

Nitter-Hauge S, Enge I, SembBK, Hall KV. 1979. Primary clinical experience with the Hall-Kaster valve in the aortic position: results at 3 months including hemodynamic studies. Circulation 60:55-62.

Puskas J, Gerdisch M, Nichols D, et al. 2014. Reduced anticoagulation after mechanical aortic valve replacement: interim results from the prospective randomized on- $\mathrm{X}$ valve anticoagulation clinical trial randomized Food and Drug Administration investigational device exemption trial. J Thorac Cardiovasc Surg 147:1202-10.
Puskas JD, Gerdisch M, Nichols D, et al. Anticoagulation and Antiplatelet Strategies After On-X Mechanical Aortic Valve Replacement. J Am Coll Cardiol. 2018 Jun 19;71(24):2717-2726.

Sundt TM, Zehr KM, Dearani JA, et al. 2005. Is early anticoagulation with warfarin necessary after bioprosthetic aortic valve replacement? J Thorac Cardiovasc Surg 129: 1024-31.

Svennevig JL, Abdelnoor M, Nitter-Hauge S. 2007. Twenty-five-year experience with the Medtronic-Hall valve prosthesis in the aortic position. A follow-up cohort study of 816 consecutive patients. Circulation 116:1785-1800.

Vahanian A, Alfieri O, Andreotti F, et al. 2012. Guidelines on the management of valvular heart disease (version 2012): the Joint Task Force on the Management of Valvular Heart Disease of the European Society of Cardiology (ESC) and the European Association for Cardio-Thoracic Surgery (EACTS). Eur J Cardiothorac Surg 42: S1-S44.

Walther T, Falk V, Tigges R, et al. 2000. Comparison of On-X and SJM HP bileaflet aortic valves. J Heart Valve Dis 9:403-7.

Williams MA, Crause L, Van Riet S. 2004. A comparison of mechanical valve performance in a poorly anticoagulated community. J Card Surg 19:410-4.

Williams MA, van Riet S. 2006. The On-X heart valve: mid-term results in a poorly anticoagulated population. J Heart Valve Dis 15:80-6.

Xu Z, Wang ZP, Ou JS, Yin SL, et al. 2016. Is low anticoagulation intensity more beneficial for patients with bileaflet mechanical mitral valves? A meta-analysis. J Cardiovasc Surg (Torino). 57:90-9. 